Revista Monografias Ambientais

Santa Maria, v. 14, n. 3, Set-Dez. 2015, p. 27-41

Revista do Centro de Ciências Naturais e Exatas - UFSM

ISSN : 22361308

\title{
Diagnóstico e proposições para os resíduos sólidos urbanos de Professor Jamil, $\mathrm{GO}$
}

\author{
Diagnosis and proposals for municipal solid waste Professor Jamil, GO
}

Evaldo de Melo Ferreira ${ }^{1}$, Fernanda Viana Batista², Natan Moraes Ribeiro², Simone Costa Pfeiffer ${ }^{2}$

${ }^{1}$ Universidade Federal de Minas Gerais

${ }^{2}$ Universidade Federal de Goiás

\section{Resumo}

Como objetivo principal para a realização do presente trabalho, tem-se a proposição de medidas para mitigação das possíveis contaminações geradas pela disposição final, efetuadas com base no diagnóstico realizado, e também de rotas tecnológicas para os resíduos. As rotas tecnológicas apontadas nesse trabalho visam alternativas para a redução no volume do lixo a ser enviado ao aterro. Uma das principais ferramentas utilizadas para avaliação da área foi o Índice de Qualidade de Aterros (IQR) proposto pela Companhia Ambiental do Estado de São Paulo (CETESB) em que o lixão obteve nota igual a 1,5 em uma escala de 0 a 10. O IQR considera as características do local, a infraestrutura e condições operacionais. Além do IQR, para a execução do presente trabalho, foram feitos levantamento bibliog ráficos relacionados ao tema e também a determinação da composição gravimétrica do lixo gerado no município. Nessa última etapa, foram considerados os seguintes grupos: matéria orgânica, metal, papel, plástico, tecido e outros materiais não identificados. Com já esperado, devido aos hábitos da população, o item que apresentou maior percentual foi a matéria orgânica, correspondendo a $68,2 \%$ do total. Durante a execução desse trabalho, Professor Jamil estava em processo de análise para a realização de consórcio.

Palavras-chave: Saneamento Ambiental. Controle de impactos ambientais. Sustentabilidade.

\begin{abstract}
The main objective for the completion of this work has been to propose measures to mitigate possible contamination generated by the disposal, carried out in the diagnosis carried out, as well as technological routes for waste. Technological routes identified in this work aimed at alternatives to reduce the volume of waste being sent to landfill. One of the main tools used to assess the area was the Quality Landfill Index (QLI) proposed by Companhia Ambiental do Estado de São Paulo (CETESB) where the dump got average score of 1.5 on a scale of 0 to 10. The QLI considers local characteristics, infrastructure and operational conditions. In the QLI for the implementation of this work were made bibliographic survey related to the topic and also the determination of gravimetric composition of the waste generated in the city. In this last step, the following groups were considered: organic matter, metal, paper, plastic, fabric and other unidentified materials. With expected, due to population habits, the item with the highest percentage was organic matter, corresponding to $68.2 \%$ of the total. During the execution of this work, Professor Jamil was under review for holding consortium.
\end{abstract}

Keywords: Environmental sanitation. Control of environmental impacts. Sustainability. 
FERREIRA, E. M. et al.: Diagnóstico e proposições para...

\section{Introdução}

Os resíduos sólidos urbanos (RSU) gerados nas cidades brasileiras são em grande parte orgânicos, sendo também compostos por papéis, plásticos, madeiras, metais, vidros, entulhos, couro, tecidos e borrachas (SILVA et al., 2013). De toda a cadeia geradora de resíduos sólidos (fabricação do produto, venda, uso e descarte), a produção e o descarte final são os que exigem maior cuidado.

Do uso de matérias primas surgem os materiais provenientes do desperdício e das sobras do processo. Nessa fase e no descarte final, os aspectos ambientais passam a exigir maior cuidado com sua gestão ambiental (FERREIRA et al., 2014). A gestão ambientalmente adequada dos resíduos sólidos nos municípios do Brasil passou a ser regulamentada pela Lei Federal n. 12.305 a partir de 2 de agosto de 2010. Entre as opções de destinação final ambientalmente adequada estão a reutilização, a reciclagem, a compostagem, a recuperação e o reaproveitamento energético (BRASIL, 2010).

Algo abordado na Política Nacional dos Resíduos Sólidos (PNRS) é que para os aterros sanitários devem ser destinados apenas para rejeitos e, ainda de acordo com a lei 12.305, todos os municípios deveriam ter essa tecnologia implantada em suas áreas, até agosto de 2014. Os aterros são considerados a última das etapas do gerenciamento dos resíduos, sendo a técnica considerada de menor custo e ambientalmente mais recomendada para localidades onde há disponibilidade de área e escassez de recursos financeiros (COUTO et al., 2013). Apesar de suas características, essa tecnologia ainda é pouco utilizada no Brasil. Em Goiás há apenas dez áreas de disposição final licenciadas como aterros sanitários.

O município de Professor Jamil está localizado no Estado de Goiás, no entorno de Goiânia, entre os rios Meia Ponte e Dourados. Durante a realização desse trabalho a localidade estava em negociação com outras cidades próximas, para o estabelecimento de um consórcio que visa a construção de um aterro sanitário e por fim sua adequação com a PNRS. Como justificativa para a realização desse trabalho tem-se a necessidade de mitigação dos impactos ambientais causados na área durante seu uso e de redução do volume de resíduos a ser enviado à área de disposição final, sendo isso possível com a proposição de rotas tecnológicas para a matéria orgânica, metal, papel, plástico e tecido.

O presente trabalho teve como objetivo geral realizar o diagnóstico dos resíduos sólidos urbanos gerados no município de Professor Jamil e propor as adequações necessárias para a correta destinação dos mesmos.

\section{Metodologia}

Professor Jamil está localizado a aproximadamente $70 \mathrm{Km}$ de distância da cidade Goiânia, capital de Goiás. A área de disposição final está localizada na Latitude $17^{\circ} 17^{\prime} 31.33^{\prime \prime} \mathrm{S}$ e Longitude $49^{\circ}$ 14'3.42" O. O levantamento bibliográfico realizado teve como foco principal os artigos publicados em periódicos nacionais e internacionais da área de saneamento.

Houve, também, consulta a normas relacionadas a projeto de aterros sanitários - NBR 8419 (1992) e NBR 13896 (1997) da Associação Brasileira de Normas Técnicas (ABNT), além da Resolução № 05 de 2014, do Conselho Estadual do Meio Ambiente (CEMAm), que dispõe sobre os procedimentos de Licenciamento Ambiental dos projetos de disposição final dos resíduos sólidos urbanos, na modalidade Aterro Sanitário, nos municípios do Estado de Goiás. Foram realizadas, ainda, consultas a documentos oficiais da prefeitura, disponibilizados pela Secretaria Municipal de Meio Ambiente.

Para determinação da composição gravimétrica dos resíduos sólidos urbanos, foi realizado o quarteamento de acordo com o preconizado pelo Manual Gerenciamento Integrado de Resíduos Sólidos do Instituto Brasileiro de Administração Municipal (IBAM). Para tanto, foi coletado em uma 
quarta-feira, dia considerado de geração média, um quantitativo de lixo igual a $11 \mathrm{~kg}$. Durante o procedimento foram utilizadas luvas, máscaras, balança de precisão, pá, rastelo, tesoura e lona preta.

Em visitas técnicas à área de disposição final, autorizadas pelo prefeito e acompanhadas pelo secretário de meio ambiente, foram feitas inspeções visuais sendo que os principais aspectos observados foram os relacionados com a infraestrutura existente, as condições de operação da área, a identificação dos materiais dispostos nessa, a presença de animais e catadores, e os possíveis impactos ambientais ao solo, ar e também a saúde das pessoas que trabalham e vivem próximo à área. Outra importante fonte de informações, foi uma reunião feita com os gestores de Professor Jamil, em que o histórico de uso da área foi melhor conhecido.

Para a avaliação dos aspectos locacionais buscou-se conhecer a distância da área com relação a cidade de Professor Jamil, a residências rurais e corpos hídricos, utilizando para isso além das vistorias in loco, o software Google Earth ${ }^{\circledR}$, que possui resolução igual a $60 \mathrm{~cm}$. Para melhor visualização da distância da área de disposição final em relação à área urbana e ao corpo hídrico mais próximo e ainda a tipologia de solo da área, foi confeccionado um mapa temático no Laboratório de Processamento de Imagens e Geoprocessamento da Universidade Federal de Goiás (LAPIG-UFG). O software utilizado foi o Arcmap ${ }^{\circledR}$ versão 10.1.

O método do IQR proposto pela CETESB, que auxilia na classificação dos locais de destinação final de resíduos após o uso de um check-list respondido em vistoria, também foi utilizado no presente trabalho. Os tópicos analisados são baseados nas características locacionais, estruturais e operacionais da área. Os fatores analisados possuem diferentes pesos, sendo o resultado final obtido a partir da somatória do subtotal de cada item, o total, dividido por 13, conforme classificação apresentada no Quadro 1.

Quadro 1 - Avaliação das condições da área de disposição final de resíduos de acordo com a atribuição de notas.

\begin{tabular}{|c|c|}
\hline IQR & AVALIAÇÃO \\
\hline 0 a 6,0 & Condições inadequadas \\
\hline 6,1 a 8,0 & Condições controladas \\
\hline 8,1 a 10,0 & Condições adequadas \\
\hline
\end{tabular}

Fonte: Adaptado de CESTEB (2011).

As resoluções RDC 306 de 2004 da Agência Nacional de Vigilância Sanitária (ANVISA) e as do Conselho Nacional do Meio Ambiente (CONAMA) de № 358 de 2005 e № 448 de 2012, foram instrumentos de análise, utilizadas para a avaliação dos aspectos legais da disposição final dos resíduos de serviço de saúde (RSS) e resíduos da construção civil (RCC) gerados no município.

Após a obtenção dos dados, foi feita a comparação do encontrado nas visitas in loco com o determinado na Resolução CEMAm e demais normas, o que possibilitou a proposição de medidas de adequação e mitigação dos impactos ambientais identificados na área.

Após a última etapa de coleta de dados, foi realizada a proposição de medidas para encerramento da área utilizada na disposição final dos resíduos de Professor Jamil, com a mitigação dos possíveis impactos. Os percentuais dos diferentes grupos de resíduos (matéria orgânica, metal, papel, plástico e tecido), serviram na determinação da proposição de rotas tecnológicas.

\section{Resultados e Discussão}

A coleta dos resíduos sólidos urbanos de Professor Jamil acontece quatro vezes por semana (segunda-feira, terça-feira, quarta-feira e quinta-feira) em um caminhão compactador (Figura 1). Existem assentamentos com aproximadamente 31 famílias também atendidas pela coleta. Não existe coleta seletiva e nem coleta específica para eletrônicos, pilhas e baterias no município. A coleta dos resíduos provenientes de demolições e construções é feita pela prefeitura e esses são utilizados em erosões. Os RSS são coletados pela empresa de incineração e enviados para outro município. O tratamento desses consiste na aplicação de método, técnica ou processo que modifique as características dos riscos inerentes aos resíduos, reduzindo ou eliminando o risco de contaminação, de 
acidentes ocupacionais ou de dano ambiental (ANVISA, 2004). O processo de destinação final dos resíduos coletados no município segue processos diferenciados, conforme apresentado na figura 1.

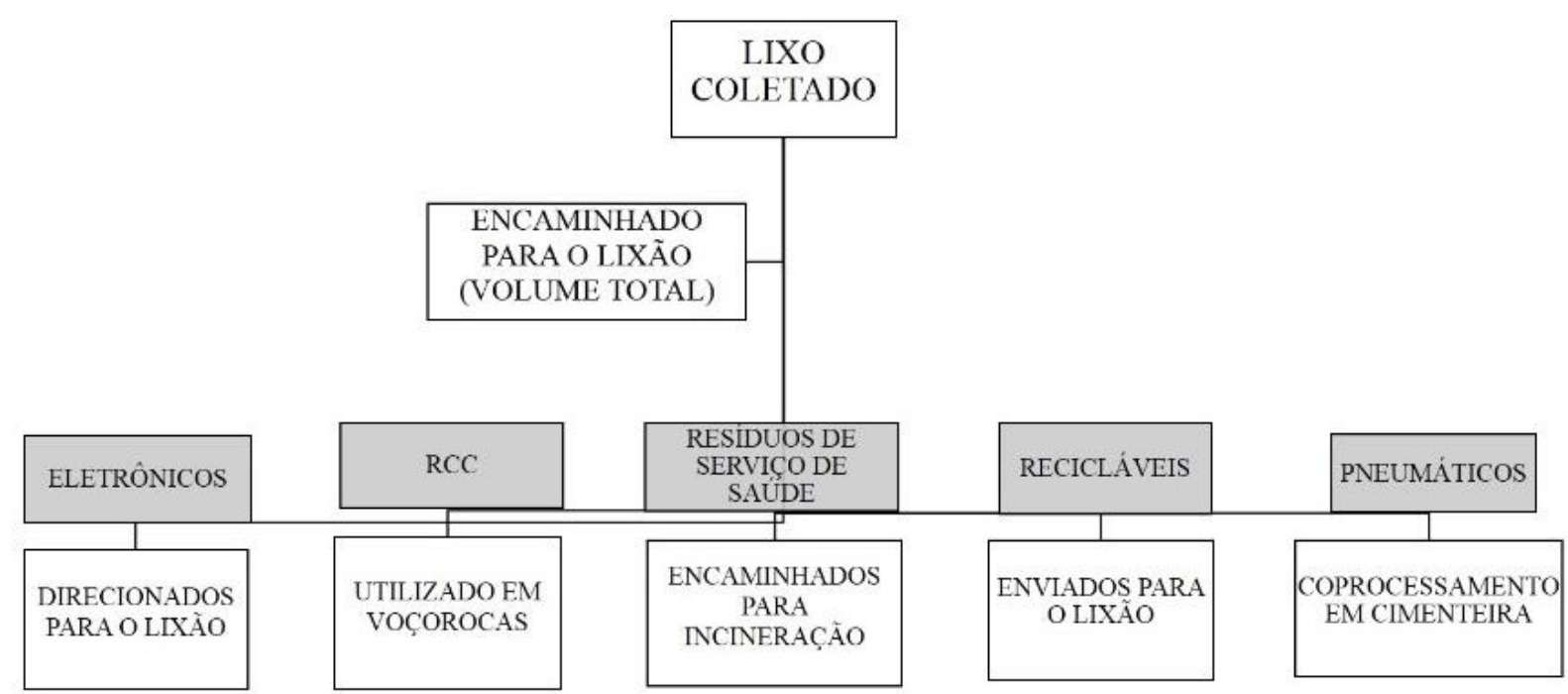

Figura 1 - Esquematização da destinação dos resíduos coletados em Professor Jamil. Fonte: Autores.

A área de disposição final de resíduos sólidos está localizada as margens da BR 153 (Figura 2). O município de Professor Jamil encontra-se em processo de consórcio com outros 20 municípios, sendo três áreas para construção do aterro sanitário e estando essas localizadas em Pontalina, Goiatuba e Morrinhos. O Plano de Gestão Integrada de Resíduos Sólidos (PGIRS) do município foi finalizado em 2012. De acordo com o PGIRS, a geração diária de resíduos sólidos em Professor Jamil é igual a $3.068,82 \mathrm{~kg}$, sendo a geração per capita igual a $0,810 \mathrm{~kg} / \mathrm{hab}$./dia. Segundo os resultados obtidos por meio do quarteamento realizado (Figuras 3 e 4), o material com maior presença foi a matéria orgânica (Figura 5). 


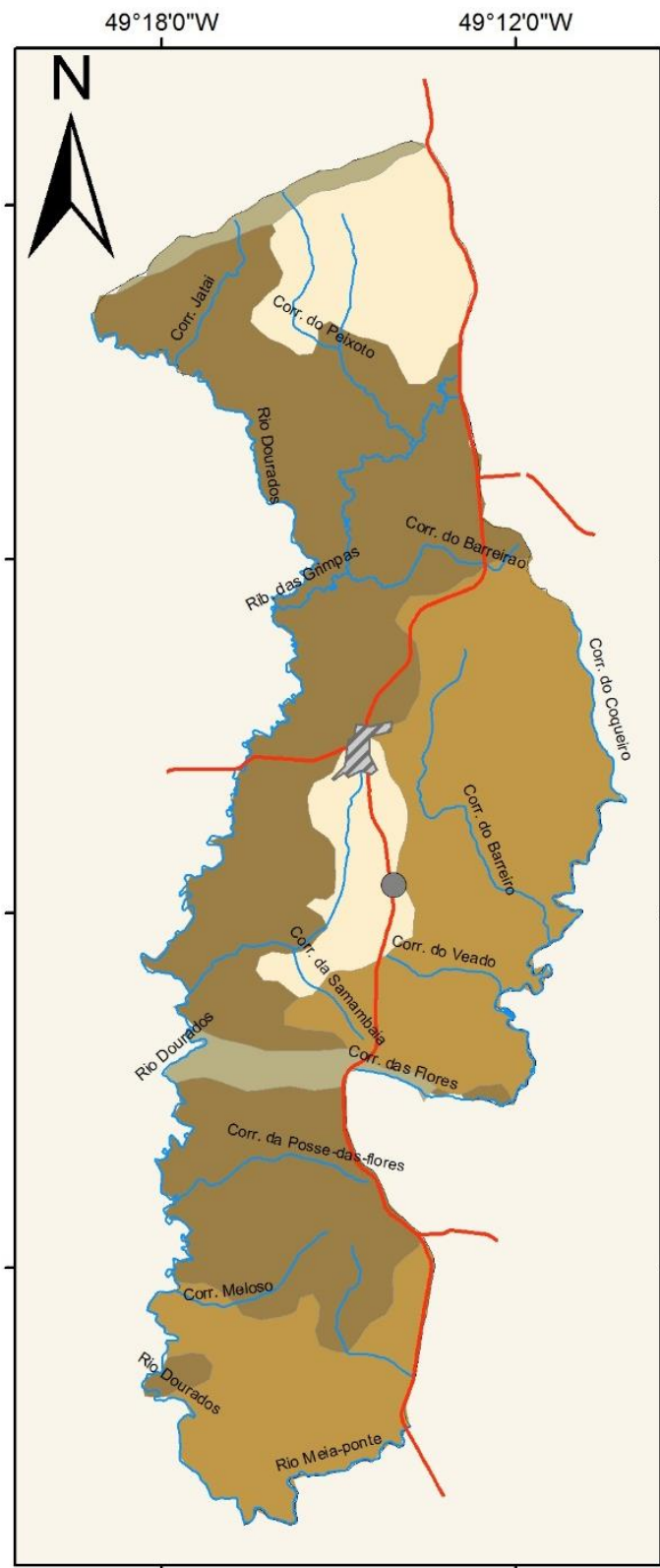

Professor Jamil / GO
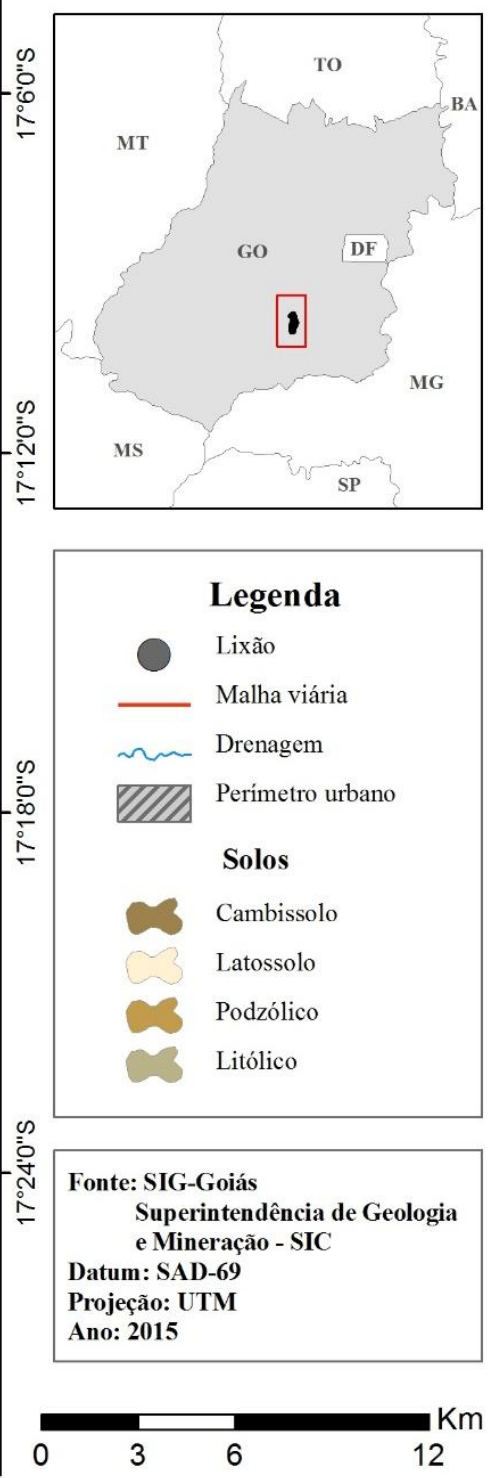

Figura 2 - Tipo de solo na área onde lixão está localizado. Fonte: Autores.

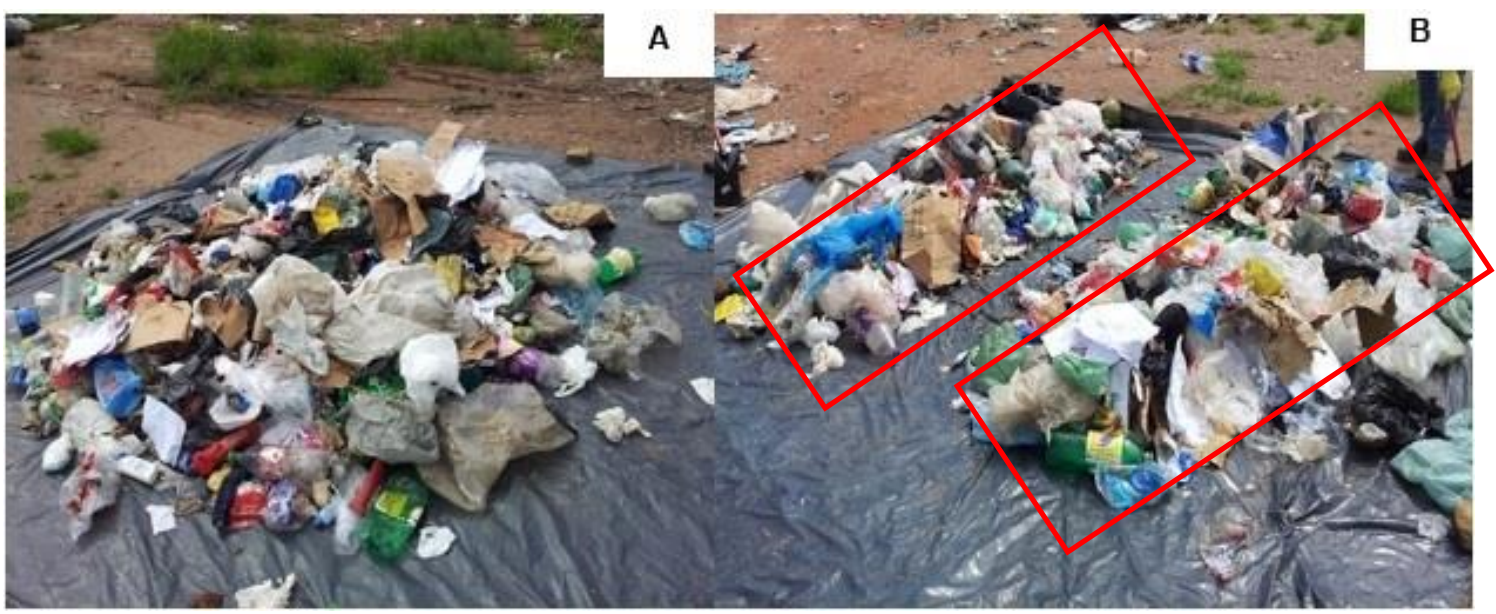

Figura 3 - A) Início do quarteamento, com o despejo do material em lona. B) Divisão do volume total em duas partes. Fonte: Autores. 


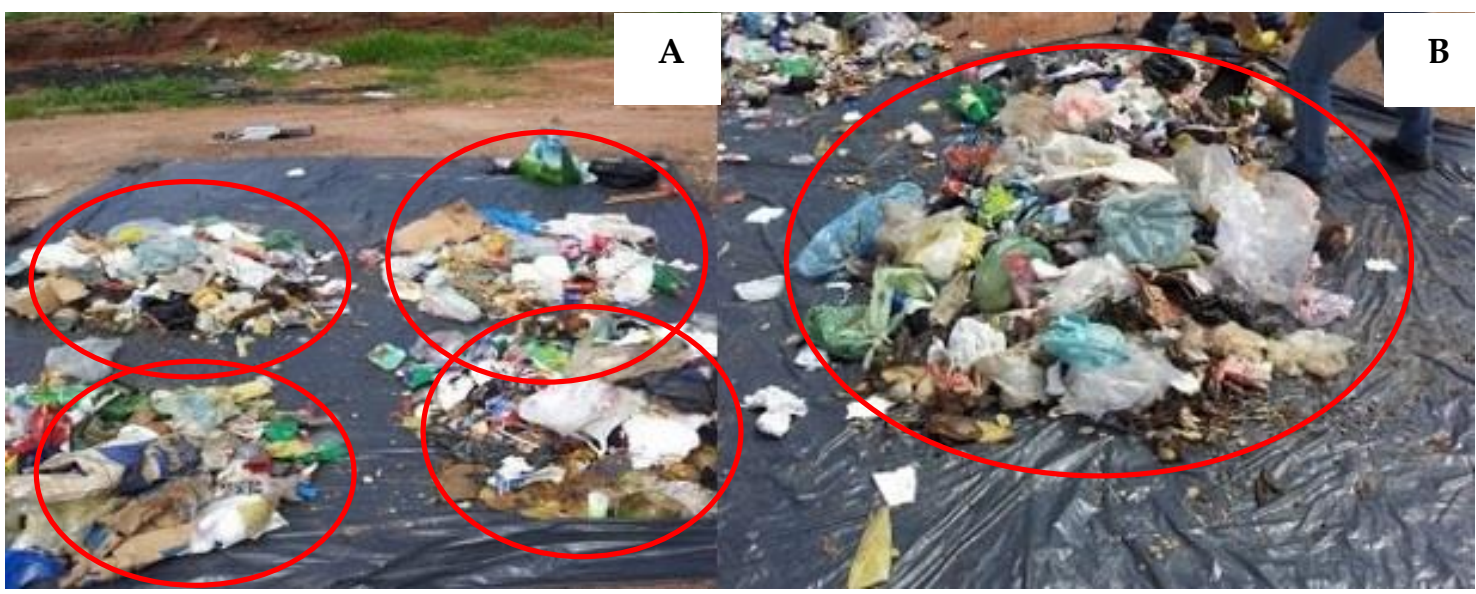

Figura 4 - A) Divisão do volume em quatro partes. B) Mistura do volume anteriormente separado para posterior divisão em dois, mistura novamente, segregação dos grupos previamente escolhidos na diagonal e por fim a pesagem desses. Fonte: Autores.

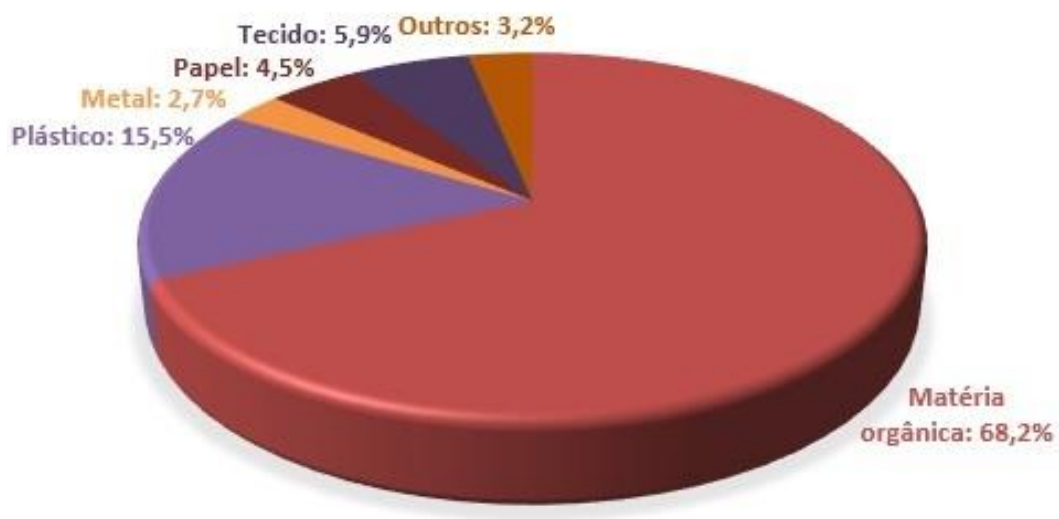

Figura 5 - Composição gravimétrica dos resíduos sólidos urbanos gerados no município de Professor Jamil. Fonte: Autores.

A área para disposição final dos resíduos sólidos possui diversos problemas, sendo observado durante as vistorias a impossibilidade de conversão da área em um aterro sanitário, pois essa não atende as condições mínimas de licenciamento estabelecidas pela Resolução CEMAm № 05 de 2014. A NBR 13896 (ABNT, 1997) estabelece que as áreas a serem utilizadas para a construção de aterros sanitários devem permitir a minimização do impacto ambiental causado por sua instalação, a maximização da aceitação da população, o local deve estar de acordo com o zoneamento da região, além de ser possível a utilização por um longo tempo, necessitando apenas de mínimo de obras para início das operações (ABNT, 1997). A área de disposição final dos materiais não possui nenhuma impermeabilização, sendo que o lixo depositado é queimado (Figura 6). Próximo a área existe também uma torre de telefonia (Figura 7). Embora não exista nenhum recobrimento do material depositado, não foram observados urubus e catadores no local.

O solo é caracterizado como latossolo, sendo um dos tipos mais adequados para utilização em áreas de disposição final de resíduos sólidos. De acordo com Ferreira et al., (2014) a presença de argila e características de solos profundos, o caracteriza como um solo mais resistente e com baixa percolação, apresentando barreiras para a contaminação do lençol freático. 


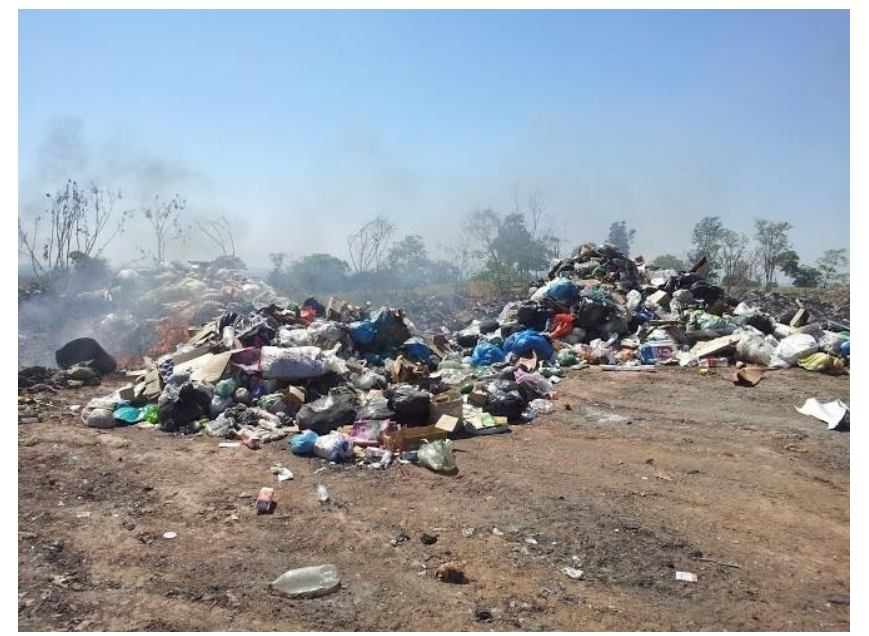

Figura 6 - Queima do material disposto no lixão de Professor Jamil. Fonte: Autores.

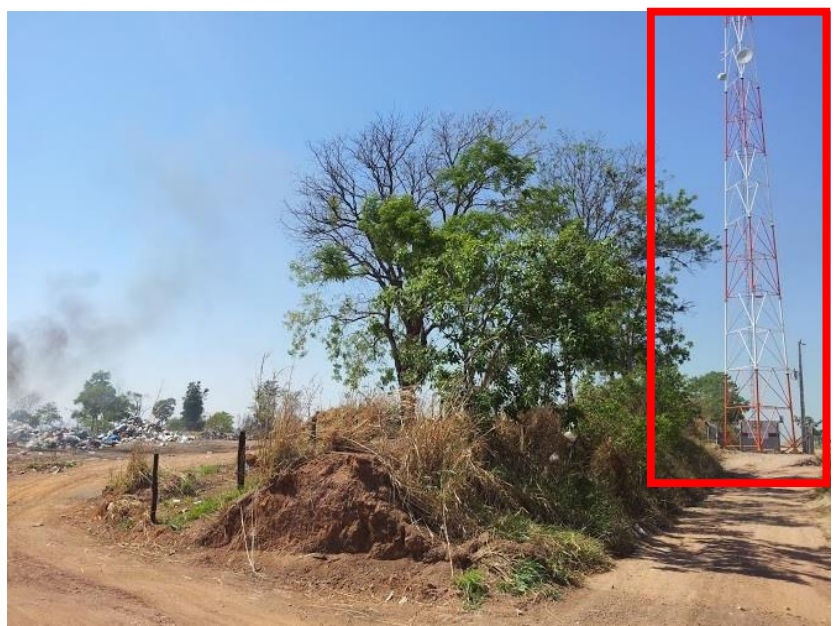

Figura 7 - Em destaque vermelho, torre de comunicação próxima a área de disposição final. Fonte: Autores.

De acordo com o secretário de meio ambiente, os resíduos de serviço de saúde (RSS) são encaminhados para uma empresa de incineração, os pneus são recolhidos e enviados para coprocessamento em uma cimenteira e os RCD são utilizados pela prefeitura para recobrimento de voçorocas. Entretanto, em uma das visitas ao lixão, foram encontrados pneus (Figura 8). Segundo a Resolução de № 358 de 2005, Para os municípios ou associações de municípios com população urbana até 30.000 habitantes, conforme dados do último censo disponível do IBGE, e que não disponham de aterro sanitário licenciado, admite-se de forma excepcional e tecnicamente motivada, por meio de Termo de Ajustamento de Conduta, com cronograma definido das etapas de implantação e com prazo máximo de três anos, a disposição final em solo de RSS obedecendo aos critérios mínimos estabelecidos no anexo II da Resolução, com a devida aprovação do órgão ambiental competente.

Em relação aos pneus, algo previsto para o Brasil, tanto para municípios de pequeno, médio e grande porte, é o aumento no volume descartado, isso devido ao aumento na frota de veículos. Com o desenvolvimento de novas tecnologias para a utilização dos materiais reciclados e a valorização energética, houve o aumento do número de empresas cadastradas no IBAMA com o foco de reciclar esses materiais (LAGARINHOS \& TENÓRIO, 2013). Além disso, mesmo não sendo grande o volume de RCD, é essencial a existência de uma alternativa que não seja a disposição em voçorocas. Nos municípios brasileiros esses materiais podem corresponder a 50\% do volume de lixo gerado (LASSO et al., 2013).

De acordo com a CONAMA de № 448, de 18 de janeiro de 2012, os resíduos da construção civil não poderão ser dispostos em aterros de resíduos sólidos urbanos, em áreas de "bota fora", em encostas, corpos d'água, lotes vagos e em áreas protegidas por Lei. Quando utilizado no recobrimento 
de voçorocas, algumas das possíveis consequências são a contaminação do lençol freático por restos de tintas e outros tipos de materiais não inertes, além do carreamento de RCDs para áreas que estão em uma cota abaixo da área de disposição.

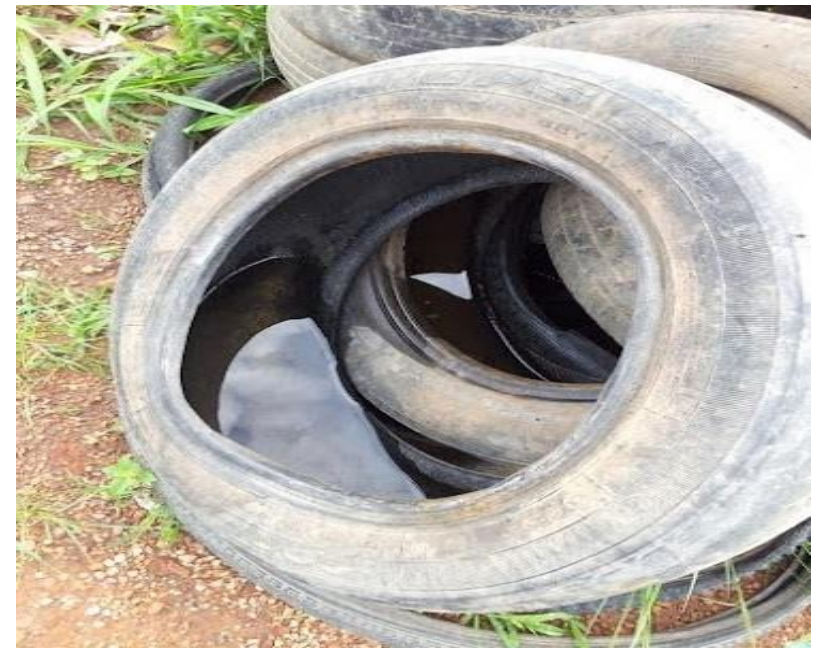

Figura 8 - Pneus encontrados na área do lixão. Fonte: Autores.

Para avaliação dos aspectos locacionais da área, foi utilizada a Resolução CEMAm № 5 de 2014. Segundo esta resolução, que estabelece distâncias mínimas entre a área de disposição dos resíduos e outros pontos, o aterro deve ficar distante $3,0 \mathrm{~km}$ do perímetro urbano de centros urbanos. De acordo com o PGIRS, o lixo é descartado em área distante aproximadamente 3,5 km do centro de Professor Jamil. Em imagens do Google Earth ${ }^{\circledR}$ essa distância foi confirmada.

A distância estabelecida para imóveis rurais, necessária ao licenciamento da área na CEMAm, é de 500 metros. A inspeção no local e levantamento das imagens no Google Earth ${ }^{\circledR}$ permitiram identificar residências rurais nas proximidades, sendo a mais próxima localizada a $0,69 \mathrm{~km}$. Diversos problemas estão relacionados a existência de moradias próximas à áreas de disposição final de resíduos. Em estudo realizado no Estado de São Paulo, essa proximidade foi a causa de óbitos, câncer de bexiga, câncer hepático, leucemia em adultos, leucemia em crianças e também má formações congênitas, isso devido a decomposição de matéria orgânica presente no lixo que além de resultar na formação do chorume, pode formar gases tóxicos, asfixiantes e explosivos, que se acumulam no subsolo ou são lançados na atmosfera (GOUVEIA \& PRADO, 2010).

Com relação aos mananciais hídricos deve-se considerar a distância mínima de $300 \mathrm{~m}$. Quando a área definida estiver à montante da captação de abastecimento público deverá manter uma distância mínima de 2.500 metros desse ponto e afastamento de 500 metros do corpo hídrico. Segundo dados do PGIRS, o abastecimento é feito pela Empresa de Saneamento de Goiás (SANEAGO) estando a captação a $4 \mathrm{~km}$ da área de disposição final de Professor Jamil. O corpo hídrico utilizado é o Rio Dourados. O manancial mais próximo da área de disposição está localizado a aproximadamente 4,71 $\mathrm{km}$.

Para área localizada na zona de amortecimento de Unidade de Conservação (Ucs), deve-se obter anuência do órgão gestor da referida unidade, conforme previsto na resolução CONAMA no 428/2010 ou sua atualização. Em relação as UCs, não existe unidades de conservação no município em questão. A declividade da área foi identificada visualmente no momento da vistoria e por meio do Google Earth ${ }^{\circledR}$ pode-se afirmar que o terreno possui pequena declividade, não superando o preconizado na CEMAm, declividade menor que 20\%. Para melhor avaliação da área de disposição final, foi realizado o cálculo do IQR para o município, onde foram considerados os aspectos locacionais, estruturais e operacionais. Os resultados podem ser vistos no Quadros 2, 3 e 4. 
Quadro 2 - Características locais da área de disposição do município de Professor Jamil.

\begin{tabular}{|c|c|c|c|c|}
\hline ÍTEM & SUB-ÍTEM & AVALIAÇÃ̃O & PESO & PONTOS \\
\hline & \multirow{2}{*}{$\begin{array}{l}\text { CAPACIDADE SUPORTE DO } \\
\text { SOLO }\end{array}$} & ADEQUADA & 5 & 5 \\
\hline & & INADEQUADA & 0 & \\
\hline & \multirow{2}{*}{$\begin{array}{l}\text { PROXIMIDADE DE NÚCLEOS } \\
\text { HABITACIONAIS }\end{array}$} & LONGE $>500 \mathrm{~m}$ & 5 & 5 \\
\hline \multirow{3}{*}{$\begin{array}{l}\mathbf{C} \\
\mathbf{A} \\
\mathbf{R}\end{array}$} & & PRÓXIMO & 0 & \\
\hline & \multirow{2}{*}{$\begin{array}{l}\text { PROXIMIDADE DE CORPOS } \\
\text { DÁGUA }\end{array}$} & LONGE $>200 \mathrm{~m}$ & 3 & 3 \\
\hline & & PRÓXIMO & 0 & \\
\hline \multirow{2}{*}{$\begin{array}{l}\text { A } \\
\text { C } \\
\text { T }\end{array}$} & \multirow{3}{*}{$\begin{array}{l}\text { PROFUNDIDADE DO LENÇOL } \\
\text { FREÁTICO }\end{array}$} & MAIOR 3m & 4 & \\
\hline & & DE 1 a $3 \mathrm{~m}$ & 2 & \\
\hline \multirow{4}{*}{$\begin{array}{l}\mathbf{E} \\
\mathbf{R} \\
\mathbf{I} \\
\mathbf{S}\end{array}$} & & DE 0 a $3 \mathrm{~m}$ & 0 & 0 \\
\hline & \multirow{3}{*}{ PERMEABILIDADE DO SOLO } & BAIXA & 5 & $\mathrm{NA}$ \\
\hline & & MÉDIA & 2 & NA \\
\hline & & ALTA & 0 & NA \\
\hline \multirow{3}{*}{$\begin{array}{l}\text { T } \\
\text { I } \\
\text { C }\end{array}$} & \multirow{3}{*}{$\begin{array}{l}\text { DISPONIBILIDADE DE } \\
\text { MATERIAL PARA } \\
\text { RECOBRIMENTO }\end{array}$} & SUFICIENTE & 4 & \\
\hline & & \begin{tabular}{|l|} 
INSUFICIENTE \\
\end{tabular} & 2 & 2 \\
\hline & & NENHUMA & 0 & \\
\hline \multirow[t]{2}{*}{$\mathbf{S}$} & \multirow{2}{*}{$\begin{array}{l}\text { QUALIDADE DO MATERIAL } \\
\text { PARA RECOBRIMENTO }\end{array}$} & BOA & 2 & \\
\hline & & RUIM & 0 & 0 \\
\hline \multirow[t]{2}{*}{$\mathbf{O}$} & \multirow{3}{*}{$\begin{array}{l}\text { CONDIÇÕES DE SISTEMA } \\
\text { VIÁRIO, TRÂNSITO E ACESSO }\end{array}$} & BOAS & 3 & 3 \\
\hline & & IRREGULARES & 2 & \\
\hline \multirow{6}{*}{$\begin{array}{l}\mathbf{L} \\
\mathbf{O} \\
\mathbf{C} \\
\mathbf{A} \\
\mathbf{L}\end{array}$} & & RUINS & 0 & \\
\hline & ISOLAMENTO VISUAL DA & BOM & 4 & \\
\hline & VIZINHANÇA & RUIM & 0 & 0 \\
\hline & LEGALIDADE DE & LOCAL PERMITIDO & 5 & \\
\hline & LOCALIZAÇÃO & LOCAL PROIBIDO & 0 & 0 \\
\hline & TOTAL & & & 18 \\
\hline
\end{tabular}

Fonte: Adaptado de CETESB (2011).

A queima do lixo, a deposição desses materiais sem cobertura, a inexistência de proteção do solo contra a infiltração de percolados que, além de contaminar o solo, também contaminam a água uma vez que o lençol freático da região é relativamente raso, são alguns dos principais problemas apontados na área.

Com base nos aspectos determinados pela resolução CEMAm de número 5, não seria possível a adaptação da área para um aterro sanitário, porém algo necessário é o encerramento dessa, ou mesmo a adequação temporária, até o prazo de ser construído do aterro sanitário que será feito em consórcio com os municípios de Água Limpa, Aloândia, Bom Jesus de Goiás, Buriti Alegre, Cachoeira Dourada, Caldas Novas, Cromínia, Edealina, Edéia, Goiatuba, Itumbiara, Joviânia, Marzagão, Morrinhos, Panamá, Piracanjuba, Pontalina, Porteirão, Professor Jamil, Rio Quente e Vicentinópolis. Considerando o porte do município e também o volume de lixo coletado, cerca de $92.064,72 \mathrm{~kg} / \mathrm{mês}$, algumas medidas podem ser adotadas na redução de impactos ambientais. 
Quadro 3 - Infraestrutura da área de disposição do município de Professor Jamil.

\begin{tabular}{|c|c|c|c|c|}
\hline ÍTEM & SUB-ITEM & AVALIAÇÃo & PESO & PONTOS \\
\hline \multirow{15}{*}{2} & \multirow{2}{*}{ CERCAMENTO DA ÁREA } & SIM & 2 & \\
\hline & & NÃO & 0 & 0 \\
\hline & \multirow{2}{*}{ PORTARIA / GUARTA } & SIM & 2 & \\
\hline & & NÃO & 0 & 0 \\
\hline & \multirow{2}{*}{$\begin{array}{l}\text { IMPERMEABILIZAÇÃO DA BASE } \\
\text { DO ATERRO }\end{array}$} & SIM / DESNECES. & 5 & \\
\hline & & NÃO & 0 & 0 \\
\hline & \multirow{3}{*}{ DRENAGEM DO CHORUME } & SUFICIENTE & 5 & \\
\hline & & INSUFICIENTE & 1 & \\
\hline & & INEXISTENTE & 0 & 0 \\
\hline & \multirow{3}{*}{$\begin{array}{l}\text { DRENAGEM DE ÁGUAS } \\
\text { PLUVIAIS DEFINTIVA }\end{array}$} & SUFICIENTE & 4 & \\
\hline & & INSUFICIENTE & 2 & \\
\hline & & INEXISTENTE & 0 & 0 \\
\hline & \multirow{3}{*}{$\begin{array}{l}\text { DRENAGEM DE ÁGUAS } \\
\text { PLUVIAIS PROVISÓRIA }\end{array}$} & SUFICIENTE & 2 & \\
\hline & & INSUFICIENTE & 1 & \\
\hline & & INEXISTENTE & 0 & 0 \\
\hline \multirow{3}{*}{$\begin{array}{l}\text { I } \\
N \\
F \\
R\end{array}$} & \multirow{3}{*}{$\begin{array}{l}\text { TRATOR DE ESTEIRAS OU } \\
\text { COMPATÍVEL }\end{array}$} & PERMANENTE & 5 & \\
\hline & & PERIODICAMENTE & 2 & \\
\hline & & INEXISTENTE & 0 & 0 \\
\hline $\mathrm{E}$ & \multirow{2}{*}{ OUTROS EQUIPAMENTOS } & SIM & 1 & \\
\hline$S$ & & NÃO & 0 & 0 \\
\hline $\begin{array}{l}T \\
R\end{array}$ & \multirow{2}{*}{$\begin{array}{l}\text { SISTEMA DE TRATAMENTO DE } \\
\text { CHORUME }\end{array}$} & SUFICIENTE & 5 & \\
\hline $\begin{array}{l}U \\
T\end{array}$ & & INSUF. / INEXIST. & 0 & 0 \\
\hline u & \multirow{2}{*}{$\begin{array}{l}\text { ACESSO À FRENTE DE } \\
\text { TRABALHO }\end{array}$} & BOM & 3 & 3 \\
\hline $\mathbf{R}$ & & RUIM & 0 & \\
\hline & \multirow{2}{*}{ VIGILANTES } & SIM & 1 & \\
\hline & & NÃO & 0 & 0 \\
\hline & \multirow{3}{*}{$\begin{array}{l}\text { SISTEMA DE DRENAGEM DE } \\
\text { GASES }\end{array}$} & SUFICIENTE & 3 & \\
\hline & & INSUFICIENTE & 1 & \\
\hline & & INEXISTENTE & 0 & 0 \\
\hline & \multirow{2}{*}{$\begin{array}{l}\text { CONTROLE RECEBIMENTO DE } \\
\text { CARGAS }\end{array}$} & SIM & 2 & \\
\hline & & NÃO & 0 & 0 \\
\hline & \multirow{3}{*}{$\begin{array}{l}\text { MONITORAÇÃO DE ÁGUAS } \\
\text { SUBTERRAANEAS }\end{array}$} & SUFICIENTE & 3 & \\
\hline & & INSUFICIENTE & 2 & \\
\hline & & INEXISTENTE & 0 & 0 \\
\hline & \multirow{3}{*}{$\begin{array}{l}\text { ATENDIMENTO A ESTIPULAÇÕES } \\
\text { DE PROJETO }\end{array}$} & SIM & 2 & \\
\hline & & PARCIALMENTE & 1 & \\
\hline & & NÃO & 0 & 0 \\
\hline & TOTAL & & & 3 \\
\hline
\end{tabular}

Fonte: CETESB (2011). 
Quadro 4 - Condições operacionais da área de disposição do município de Professor Jamil.

\begin{tabular}{|c|c|c|c|c|}
\hline ÍTEM & SUB-ÍTEM & AVALIAÇÃ̃o & PESO & PONTOS \\
\hline & \multirow{2}{*}{ ASPECTO GERAL } & BOM & 4 & \\
\hline & & RUIM & 0 & 0 \\
\hline & \multirow{2}{*}{$\begin{array}{l}\text { OCORRÊNCIA DE LIXO } \\
\text { A DESCOBERTO }\end{array}$} & NÃO & 4 & \\
\hline & & SIM & 0 & 0 \\
\hline & \multirow{3}{*}{$\begin{array}{l}\text { RECOBRIMENTO DO } \\
\text { LIXO }\end{array}$} & ADEQUADO & 4 & \\
\hline & & INADEQUADO & 1 & 1 \\
\hline & & INEXIST ENTE & 0 & \\
\hline & \multirow{2}{*}{$\begin{array}{l}\text { PRESENÇA DE URUBUS } \\
\text { OU GAIVOT AS }\end{array}$} & NÃO & 1 & \\
\hline & & SIM & 0 & 0 \\
\hline & \multirow{2}{*}{$\begin{array}{l}\text { PRESENÇA DE MOSCAS } \\
\text { EM GRANDE } \\
\text { QUANTIDADE }\end{array}$} & NÃO & 2 & \\
\hline & & SIM & 0 & 0 \\
\hline & \multirow{2}{*}{$\begin{array}{l}\text { PRESENÇA DE } \\
\text { CAT ADORES }\end{array}$} & NÃO & 3 & 3 \\
\hline \multirow{3}{*}{$\begin{array}{l}\mathbf{C} \\
\mathbf{O} \\
\mathbf{N}\end{array}$} & & SIM & 0 & \\
\hline & \multirow{2}{*}{$\begin{array}{l}\text { CRIAÇÃO DE ANIMAIS } \\
\text { (PORCOS, BOIS) }\end{array}$} & NÃO & 3 & 3 \\
\hline & & SIM & 0 & \\
\hline $\begin{array}{l}\text { D } \\
\text { I }\end{array}$ & \multirow{2}{*}{$\begin{array}{l}\text { DESCARGA DE } \\
\text { RESÍDUOS DE SERVIÇO } \\
\text { DE SAÚDE }\end{array}$} & NÃO & 3 & 3 \\
\hline$\underset{\widetilde{C}}{\text { Con }}$ & & SIM & 0 & \\
\hline $\begin{array}{l}\mathbf{O} \\
\mathbf{E}\end{array}$ & \multirow{2}{*}{$\begin{array}{l}\text { DESCARGA DE } \\
\text { RESÍDUOS INDUST RIAIS }\end{array}$} & NÃO / ADEQUADA & 4 & 4 \\
\hline S & & SIM / INADEQUADA & 0 & \\
\hline \multirow{21}{*}{$\begin{array}{l}\mathbf{O} \\
\mathbf{P} \\
\mathbf{E} \\
\mathbf{R} \\
\mathbf{A} \\
\mathbf{C} \\
\mathbf{I} \\
\mathbf{O} \\
\mathbf{N} \\
\mathbf{A} \\
\mathbf{I} \\
\mathbf{S}\end{array}$} & \multirow{3}{*}{$\begin{array}{l}\text { FUNCIONAMENTO DA } \\
\text { DRENAGEM PLUVIAL } \\
\text { DEFINITIVA }\end{array}$} & BOM & 2 & \\
\hline & & IRREGULAR & 1 & \\
\hline & & INEXISTENTE & 0 & 0 \\
\hline & \multirow{3}{*}{$\begin{array}{l}\text { FUNCIONAMENTO DA } \\
\text { DRENAGEM PLUVIAL } \\
\text { PROVISÓRIA }\end{array}$} & BOM & 2 & \\
\hline & & IRREGULAR & 1 & \\
\hline & & INEXISTENTE & 0 & 0 \\
\hline & \multirow{3}{*}{$\begin{array}{l}\text { FUNCIONAMENTO DA } \\
\text { DRENAGEM DE } \\
\text { CHORUME }\end{array}$} & BOM & 3 & \\
\hline & & REGULAR & 2 & \\
\hline & & INEXISTENTE & 0 & 0 \\
\hline & \multirow{3}{*}{$\begin{array}{l}\text { FUNCIONAMENTO DO } \\
\text { SISTEMA DE } \\
\text { TRAT AMENTO DE } \\
\text { CHORUME }\end{array}$} & BOM & 5 & \\
\hline & & REGULAR & 2 & \\
\hline & & INEXISTENTE & 0 & 0 \\
\hline & \multirow{3}{*}{$\begin{array}{l}\text { FUNCIONAMENTO DO } \\
\text { SIST. DE } \\
\text { MONITORAÇÃO DE } \\
\text { ÁGUAS SUBTERRÂNEAS } \\
\end{array}$} & BOM & 2 & \\
\hline & & REGULAR & 1 & \\
\hline & & INEXISTENTE & 0 & 0 \\
\hline & \multirow{2}{*}{$\begin{array}{l}\text { EFICIENCIA DA } \\
\text { EQUIPE DE } \\
\text { VIGILÂNCIA }\end{array}$} & $\mathrm{BOA}$ & 1 & \\
\hline & & RUIM & 0 & 0 \\
\hline & \multirow{3}{*}{$\begin{array}{l}\text { MANUTENÇÃO DOS } \\
\text { ACESSOS INTERNOS }\end{array}$} & BOAS & 2 & \\
\hline & & REGULARES & 1 & 1 \\
\hline & & PÉSSIMAS & 0 & \\
\hline & TOTAL & & & 15 \\
\hline
\end{tabular}

Fonte: CETESB (2011).

Por meio dos três subitens respondidos foi possível calcular o IQR da área de estudo (Equação 1). $\mathrm{IQR}=($ Sub1 + Sub $2+$ Sub 3) $/ 13$ (Equação 1)

Onde:

Sub1 é o subtotal do primeiro quadro;

Sub2 é o subtotal do segundo quadro; e

Sub 3 é o subtotal do terceiro quadro. 
Logo:

$$
\begin{gathered}
\mathrm{IQR}=18+3+15 / 13 \\
\mathrm{IQR}=2,7
\end{gathered}
$$

Para as melhorias na deposição do lixo sobre o solo, a utilização de valas seria o mais adequado, pois essas são inexistentes na área. O recobrimento do lixo com RCDs é uma das opções para o recobrimento desses materiais, pois o recobrimento com solo, mesmo sendo o adequado, poderia encarecer essa atividade e impossibilitar a ação. Não existem maquinários permanentes no lixão, sendo isso necessário e também possível de ser adquirido pelo município. Outro importante aspecto é o controle de entrada e também saída de materiais e pessoas na área. Não existe na área um funcionário específico para isso, facilitando deposições sem autorização e queimadas que, segundo o secretário de meio ambiente do município, é bem comum de ocorrer na área.

Caso a área obedecesse as condições mínimas presentes na resolução CEMAm, alguns dos fatores importantes a serem considerados na sua utilização como aterro sanitário, seriam: impermeabilização das valas, construção de sistema para a drenagem do percolado líquido e dos gases, construção de lagoa para recebimento e tratamento do chorume, construção de sistema para captação do material tratado, análise da capacidade de autodepuração e também resiliência do corpo receptor, remoção de catadores e animais, construção de vias para o trânsito de veículos, estabelecimento de uma nova cerca viva, galpão coberto para recebimento dos recicláveis, construção de sede administrativa e balança para pesagem dos caminhões que chegam com os resíduos (FERREIRA et al., 2014).

Após o encerramento das atividades na área, algo obrigatório é o monitoramento dos impactos ambientais no lenço freático causado pelo percolado, além do monitoramento dos gases causadores de efeito estufa. Para o primeiro problema, uma das soluções é o uso de poços de monitoramento. Esses devem ser perfurados até que cheguem no nível do lençol freático e caso exista o risco de contaminação de algum ponto de abastecimento, tecnologias de remediação devem ser aplicadas e também a interrupção do uso se fará necessária. Os gases devem captados e queimados, sendo o adequado a existência de um sistema que possibilite o aproveitamento energético, porém, se analisarmos as finanças do município e também o mercado em potencial, talvez o aproveitamento energético não seja viável.

Após a realização do quarteamento, os dois principais resíduos encontrados foram a matéria orgânica e o plástico, seguidos do tecido, papel, outros materiais não identificados e metal.

Uma das alternativas apontadas para a matéria orgânica é a compostagem. Entre outros benefícios, o processo de compostagem reduz as emissões de gases efeito estufa, que com a correta umidade, temperatura e também arejamento do material (fatores que afetam a eficiência do processo), reduz as emissões de $\mathrm{CH} 4$, por exemplo (ERMOLAEV et al., 2014). Essa rota tecnológica é viável para o município, pois além de dispor de área para uma composteira, também existe próximo à área urbana, propriedades rurais que são potenciais compradores desses materiais.

O processo de compostagem poderia ser realizado com o uso dos restos de alimentos presentes no lixo gerado pela população, que corresponde a $68,2 \%$, além de elementos de poda e serragem de marcenarias da cidade, por exemplo. Compostos orgânicos como restos de madeiras e alguns vegetais, quando compostados são facilmente degradados, contribuindo para a massa final do composto (ZHOU et al., 2014). Alguns dos fatores que trazem aumento no processo de compostagem são: aumento da geração dos resíduos, limitação de espaço para a construção de aterros e políticas ambientais mais rigorosas (AWASTHI et al., 2014).

Algo agronomicamente aceito, é o uso desses materiais em pastagens, sendo que a logística para isso seria facilitada, devido a existência de criação bovina em área próximas. Antes da aplicação do composto no solo, análises laboratoriais devem ser feitas. O percolado gerado ainda é um dos principais problemas da aplicação de resíduos no solo, onde após a degradação do material orgânico, há a geração de um líquido altamente poluidor e de alta carga orgânica e inorgânica, com alta variabilidade composicional, destacando-se a presença de nutrientes como o nitrogênio, fósforo, potássio, alguns micronutrientes, além de matéria orgânica, que são positivos para a cultura (MATOS et al., 2013). 
O município de Professor Jamil não possui compradores em potencial para o plástico. Não existem fabricantes de plástico próximo à Professor Jamil. Como fim para os plásticos gerados na cidade, temse o aterro sanitário. Para o conhecimento dos materiais passíveis de reciclagem, alguns produtos apresentam um código de identificação da resina utilizada na fabricação. O código é um número de um a sete dentro de um triângulo de três setas e sob o mesmo uma abreviatura, cujo objetivo é indicar o tipo particular de plástico do qual o produto é feito. Os códigos de identificação têm por objetivo facilitar a recuperação das embalagens plásticas descartadas com o resíduo sólido urbano, uma vez que auxiliam sua separação e posterior reciclagem e revalorização, porém poucas pessoas tem conhecimento disso (COLTRO \& DUARTE, 2013).

Os restos de tecido provenientes de confecções possuem alto potencial de reaproveitamento pelas próprias empresas produtoras de roupas, por exemplo. De acordo com o PGIRS de Professor Jamil, tecidos, papéis, plásticos, vidros e metais, correspondem a cerca de $52,81 \%$ do percentual coletado.

Os resíduos de papel encontrados no processo de quarteamento possuem baixo potencial para reciclagem, sendo esses em grande parte embalagens de industrializados com alto teor de plástico. Os processos de reciclagem tem custos diretos acrescidos para os agentes dos setores público e também privado, que são traduzidos em preços de produtos embalados mais elevados ou no acréscimo das tarifas ou impostos afetos à gestão do lixo urbano. Um dos principais aspectos negativos é o baixo valor de mercado dos produtos recicláveis de resíduos de embalagens, especialmente para os casos em que as matérias-primas são de baixo custo (CRUZ \& MARQUES, 2014).

Entre os materiais encontrados com alto potencial para reciclagem estão os metais. O alumínio foi o de maior presença. Diferente do encontrado pela empresa responsável pelo PGIRS do município, não foram encontrados resíduos de borracha. Como alternativa para destinação final dos diferentes materiais, sendo considerada a existência de um aterro sanitário especialmente para os resíduos de Professor Jamil e sem a existência de um consórcio, tal como no indicado na figura a seguir (Figura 9).

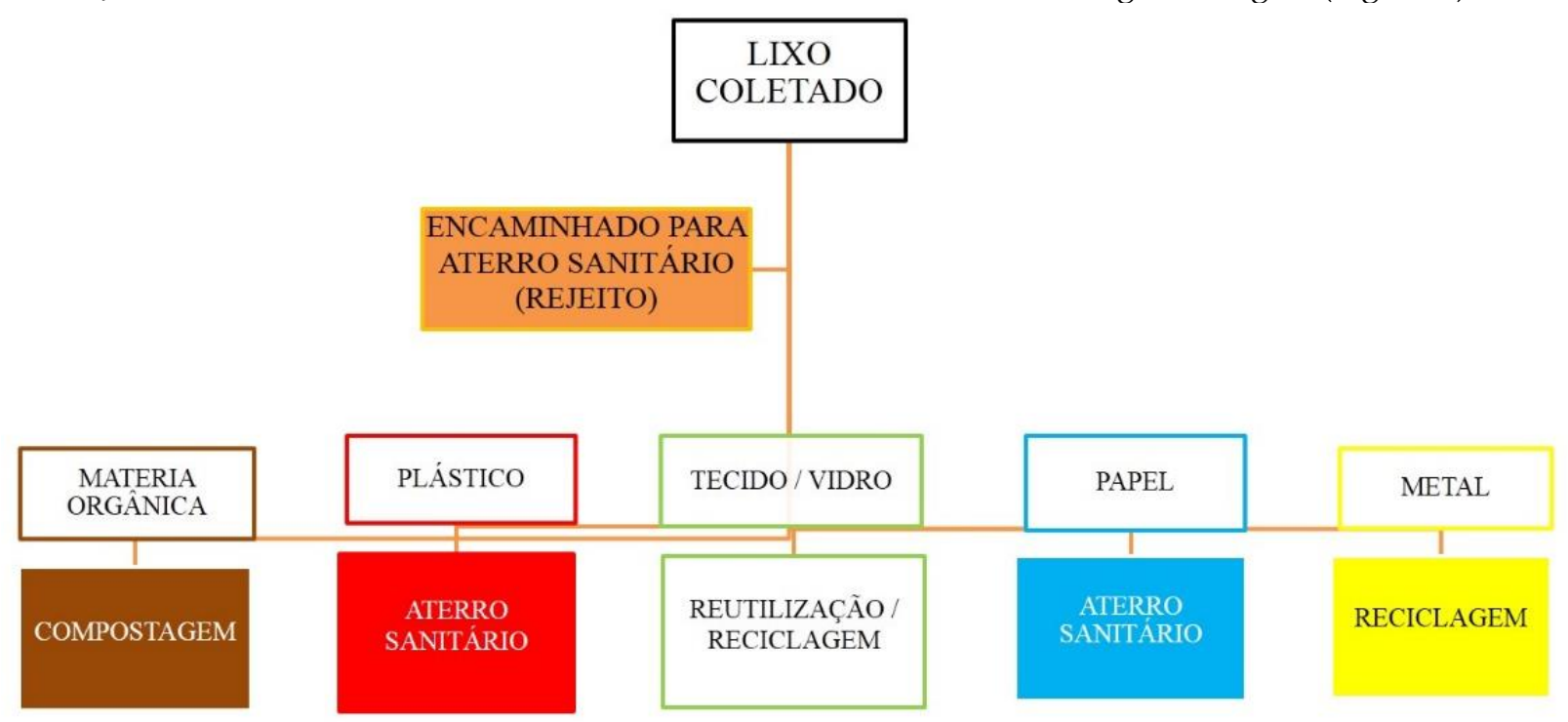

Figura 9 - Alternativas para os diferentes resíduos considerando a existência de um aterro sanitário. Fonte: Autores.

\section{Conclusões}

Como apontado no trabalho, algumas medidas para controle ambiental devem ser tomadas, mesmo com a perspectiva de construção de aterro sanitário em consórcio com outros municípios. Devido à proximidade da área com residências rurais e também com a BR 153, algumas das medidas mais urgentes são o recobrimento do lixo, interrupção da queima do material depositado e também o adequado cercamento da área, visto que foi relatado pelo secretário de meio ambiente de Professor Jamil, a deposição de lixo sem autorização por parte 
de terceiros. Após a interrupção do uso da área, essa deve ser monitorada em um tempo médio de dez anos, até a estabilização do material deposto. Algo já previsto no ano de 2012 é o licenciamento de três áreas para a construção de aterros sanitários, nos municípios de Goiatuba, Morrinhos e Pontalina. Essas áreas devem obedecer ao preconizado na resolução CEMAm № 5 de 2014.

Devido a inviabilidade econômica, logística, falta de mercado e principalmente de volume gerado, para materiais como papel e plástico, o mais indicado para Professor Jamil foi o envio desses ao aterro sanitário. É possível a reciclagem da matéria orgânica, do metal e a reutilização do tecido.

\section{Referências}

ANVISA - Agência Nacional de Vigilância Sanitária. Resolução RDC No 306, de 7 de dezembro de 2004. Disponível em: <http://bvsms.saude.gov.br/bvs/saudelegis/anvisa/2004/res0306_07_12_2004.html>. Acesso em: 01 ago. 2014.

ASSOCIAÇÃO BRASILEIRA DE NORMAS TÉCNICAS. NBR 13896: Aterros de resíduos não perigosos critérios para projeto, implantação e operação. Rio de Janeiro, 1997.

NBR 8419: Apresentação de projetos de aterros sanitários de resíduos sólidos urbanos. Rio de Janeiro, 1992.

AWASTHI, M. K; PANDEY, A. K; KHAN, J; BUNDELA, P. S; WONG, J. W. C; SELVAM, A. Evaluation of thermophilic fungal consortium for organic municipal solid waste composting. Bioresource Technology-Elsevier, USA, vol. 168, p. 214-221, Sept. 2014.

BRASIL. Lei de $\mathrm{N}^{\circ} 12.305$, de 2 de agosto de 2010. Institui a Política Nacional de Resíduos Sólidos; altera a Lei no 9.605, de 12 de fevereiro de 1998; e dá outras providências. Disponível em: <http://www.planalto.gov.br/ccivil_03/_ato2007-2010/2010/lei/112305.htm>. Acesso em: 25 out. 2014.

CETESB - COMPANHIA ESTADUAL DE SÃO PAULO. Inventário Estadual de Resíduos Sólidos Urbanos, 2011. 21 ed. São Paulo: CETESB, 2011. 110 p.

CONAMA - Conselho Nacional do Meio Ambiente. Resolução № 358, de 29 de abril de 2005. Dispõe sobre o tratamento e a disposição final dos resíduos dos serviços de saúde e dá outras providências. Disponível em: 〈http://www.mma.gov.br/port/conama/res/res05/res35805.pdf〉. Acesso em: 01 ago. 2014.

Resolução de $\mathrm{N}^{\circ} 448$, de 18 de janeiro de 2012. Altera os arts. $\mathbf{2}^{\mathbf{0}}, \mathbf{4}^{\mathbf{0}}, \mathbf{5}^{\mathbf{0}}, \mathbf{6}^{\mathbf{0}}, \mathbf{8}^{\mathbf{0}}, \mathbf{9}^{\mathbf{0}}, \mathbf{1 0}$ e 11 da Resolução no 307, de 5 de julho de 2002, do Conselho Nacional do Meio Ambiente- CONAMA. Disponível em: <http://www.mma.gov.br/port/conama/legiabre.cfm?codlegi=672〉. Acesso em: 13 fev. 2015.

Resolução de $\mathrm{N}^{\circ}$ 428, de 17 de dezembro de 2010. Dispõe, no âmbito do licenciamento ambiental sobre a autorização do órgão responsável pela administração da Unidade de Conservação (UC), de que trata $o \S 3^{\circ}$ do artigo 36 da Lei $n^{0} 9.985$ de 18 de julho de 2000 , bem como sobre a ciência do órgão responsável pela administração da UC no caso de licenciamento ambiental de empreendimentos não sujeitos a EIA-RIMA e dá outras providências. Disponível em: <http://www.mma.gov.br/port/conama/legiabre.cfm?codlegi=641>. Acesso em: 10 nov. 2014.

COUTO, M. C. L.; BRAGA, F. S.; LANGE, L. C. Tratamento de lixiviado por infiltração rápida como alternativa para cidades de pequeno porte. Engenharia Sanitária e Ambiental, Rio de Janeiro, vol. 18, n. 3, p. 223-234, jul./set. 2013.

COUTRO, L \& DUARTE, L. C. Reciclagem de embalagens plásticas flexíveis: contribuição da identificação correta. Polímeros, São Carlos, vol. 23, n. 1, p. 128-134, Epub 01-Fev-2013. 
CRUZ, N. F \& MARQUES, R. C. Análise econômica do sistema da reciclagem em Portugal. Engenharia Sanitária e Ambiental, Rio de Janeiro, vol. 19, n. 3, p. 335-344, jul./set. 2014.

ERMOLAEV, E; SUNDBERG, C; PELL, M; JÖNSSON, H. Greenhouse gas emissions from home composting in practice. Bioresource Technology-Elsevier, USA, vol. 151, p. 174-182, Jan. 2014.

FERREIRA, E. M.; CRUVINEL, K. A. S.; COSTA, E. S. Disposição final dos resíduos sólidos urbanos: diagnóstico da gestão do município de Santo Antônio de Goiás. Revista Monografias Ambientais, Santa Maria, vol. 14, n. 3, p. 3401-3411, mai-ago. 2014.

GOUVEIA, N \& PRADO, R. R. Riscos à saúde em áreas próximas a aterros de resíduos sólidos urbanos. Revista de Saúde Pública, São Paulo, vol. 44, n. 5, p. 859-866, out. 2010 Epub 03-Set-2010.

IBAM - Instituto Brasileiro de Administração Municipal. Manual Gerenciamento Integrado de Resíduos Sólidos. 15. ed. Rio de Janeiro: IBAM, 2001. 200 p.

LAGARINHOS, C. A. F \& TENÓRIO, J. A. S. Logística reversa dos pneus usados no Brasil. Polímeros, São Carlos, vol. 23, n. 1, p. 49-58, 2013 Epub 11-Out-2012.

LASSO, P. R. O; VAZ, C. M. P; BERNARDI, A. C. C; OLIVEIRA, C. R; BACCHI, O. O. S. Avaliação do uso de resíduos de construção e demolição reciclados como corretivo da acidez do solo. Revista Brasileira de Ciência do Solo, Viçosa, vol. 37, n. 6, p. 1659-1668, nov./dez. 2013.

MATOS, A. T; SILVA, D. F; LO MONACO, P. A. V; PEREIRA, O. G. Produtividade e composição química do capim-Tifton 85 submetido a diferentes taxas de aplicação do percolado de resíduo sólido urbano. Engenharia Agrícola, Jaboticabal, vol. 33, n. 1, p. 188-200, jan./fev. 2013.

PROFESSOR JAMIL. Plano de gestão integrada de resíduos sólidos. Professor Jamil: Instituto Vida, Gestão Ambiental e Municipal, 2012. 61 p.

SEMARH GO - Secretaria Estadual do Meio Ambiente e dos Recursos Hídricos. Resolução No 05, de 2014. Dispõe sobre os procedimentos de Licenciamento Ambiental dos projetos de disposição final dos resíduos sólidos urbanos, na modalidade Aterro Sanitário, nos municípios do Estado de Goiás. Disponível

em: <http://www.semarh.goias.gov.br/site/uploads/files/resolu\%C3\%A7\%C3\%A3o_cemam_05_2014_aterr o.pdf>. Acesso em: 10 nov. 2014.

SILVA, T. N.; FREITAS, F. S. N.; CANDIANI, G. Avaliação das emissões superficiais do gás de aterros sanitários de grande porte. Engenharia Sanitária e Ambiental, Rio de Janeiro, vol. 18, n.2, p. 95-104, abr./jun. 2013.

ZHOU, H-B; MA, C; GAO, D; CHEN, T-B; ZHENG, G-D; CHEN, J; PAN, T-H. Application of a recyclable plastic bulking agent for sewage sludge composting. Bioresource Technology-Elsevier, USA, vol. 152, p. 329-336, Jan. 2014. 